\title{
Immunohistochemistry analysis of checkpoint kinase 2 in oral squamous cell carcinoma
}

\author{
Suziene Caroline Silva Cardoso ${ }^{1}$, Andressa Duarte ${ }^{1 *}$ (D), Luciana Yamamoto de Almeida ${ }^{2}$, Jorge Esquiche León ${ }^{3}$ and \\ Alfredo Ribeiro-Silva'
}

\begin{abstract}
Background: Oral squamous cell carcinoma (OSCC) is the most frequently occurring malignant tumor of the head and neck region. Chk2 (Checkpoint kinase 2) is considered a tumor suppressor gene that acts on the cellular response to DNA damage. However, the role of Chk2 in OSCC prognosis is not yet fully understood. The objective of this study was to evaluate Chk2 immunoexpression in OSCC and to elucidate the association between its expression and clinicopathological parameters of prognostic importance, including overall survival, disease-free survival, and metastasis-free survival.
\end{abstract}

Methods: Chk2 expression was analyzed in 101 samples from patients with OSCC using immunohistochemistry. We stratified the patients into high expression (> 66\% of cells positive for Chk2) and low expression (<66\%) groups.

Results: Chk2 showed high expression in $57.43 \%$ of OSCC. In our study, the expression of Chk2 did not correlate with any of the prognostic parameters evaluated. There was no difference between overall survival, metastasis-free survival, and disease-free survival according to Chk2 expression.

Conclusion: Despite the great importance of Chk2 in the development of different types of cancer, our findings do not favor Chk2 as a prognostic marker in oral squamous cell carcinoma.

Keywords: Checkpoint kinase 2 (Chk2), Oral squamous cell carcinoma (OSCC), Prognostic marker

\section{Introduction}

Approximately $90 \%$ of head and neck cancer originates from squamous cells. Head and neck cancer includes the oral cavity, lips, pharynx, larynx, salivary glands, ears, nasal cavity and paranasal sinuses [1]. It is associated with high morbidity and poor prognosis when diagnosed in advanced stages [2]. Head and neck cancer is the sixth most frequently occurring malignant tumor worldwide, representing $2-3 \%$ of all cases of cancers [3].

The prognosis of patients and selection of therapy are mainly based on clinical, radiological and histopathological analyses. However, the site of origin of the

\footnotetext{
* Correspondence: andressaduarte@usp.br

${ }^{1}$ Department of Pathology and Forensic Medicine, Ribeirão Preto Medical

School, University of São Paulo, Ribeirão Preto, Brazil

Full list of author information is available at the end of the article
}

primary tumor and the presence or absence of metastasis in cervical lymph nodes and distant metastases are also important parameters [4].

The Checkpoint Kinase 2 (CHECK2 or CHK2) gene encodes the Chk2 protein kinase that has the function of controlling the cell cycle through the phosphorylation of proteins such as p53, cdc25C, cdc25A, and brcal, which have functions in the response to DNA damage in the cell. There is evidence that Chk2 is associated with tumorigenesis and may be considered a tumor suppressor gene [5]. Mutations lead to truncated CHK2 protein with reduced or absent kinase activity, and mutations in cancer susceptibility genes increase the risk of developing breast, prostate, ovary, colorectal, kidney, thyroid and bladder cancers and leukemias [6].

(c) The Author(s). 2020 Open Access This article is licensed under a Creative Commons Attribution 4.0 International License, which permits use, sharing, adaptation, distribution and reproduction in any medium or format, as long as you give appropriate credit to the original author(s) and the source, provide a link to the Creative Commons licence, and indicate if changes were made. The images or other third party material in this article are included in the article's Creative Commons licence, unless indicated otherwise in a credit line to the material. If material is not included in the article's Creative Commons licence and your intended use is not permitted by statutory regulation or exceeds the permitted use, you will need to obtain permission directly from the copyright holder. To view a copy of this licence, visit http://creativecommons.org/licenses/by/4.0/. 
The lack of Chk2-dependent apoptotic signaling facilitates the propagation of mutations, thus increasing genomic instability. The first time that Chk2 was considered a tumor suppressor gene was when a rare germ mutation in the CHK2 gene that inactivates TP53 in a subpopulation of families with Li-Fraumeni syndrome (LFS) was discovered [7]. Li- Fraumeni syndrome is a hereditary cancer syndrome that is usually related to multiple cases of primary tumors in children and young adults, including sarcomas, breast carcinomas, brain tumors, leukemias, and tumors of the adrenal cortex [8]. Similar to the mutations that occur in LFS, some studies have shown that Chk2 and p53 are jointly mutated, such as in colorectal cancer [9] and mammary carcinomas [10], suggesting that Chk2 and p53 have correlated functions.

Somatic mutations of Chk2 were found in some sporadic malignant tumors, including tumors of the breast [10], colon [7], lung [11], and vulva [12], among others [13].

Squamous cell carcinoma (SCC)-related research has progressed, and several prognostic and predictive biomarkers have been described in the literature. However, so far, no single marker is unanimously accepted for routine clinical use in OSCC patients [14].

Chk2 is considered a promising target for therapeutic and prognostic purposes. Many studies have associated different types of cancers with Chk2, such as breast carcinoma [15], colorectal cancer [16], hepatocellular carcinoma [17], ovarian carcinoma [18] and bladder cancer [19]. However, the relationship between Chk2 and OSCC is still poorly understood.

The objective of this study was to evaluate Chk2 immunoexpression in OSCC and to associate its expression with clinicopathological parameters of prognostic importance, including overall survival, disease-free survival, and metastasis-free survival.

\section{Material and methods Patients}

In this study, we analyzed 101 cases of oral squamous cell carcinoma (OSCC) diagnosed between 2005 and 2015. We considered only cases whose diagnoses were made in the following regions as oral cavities: jaw, floor, retromolar, mouth, oral cavity, tongue, jugal mucosa, gum, hard palate and lip [20].

This study was approved by the local Research Ethics Committee. The clinicopathological data were obtained by analyzing the medical files of the patients. The patients' biopsies were retrieved from the archives of the Pathology Department at Ribeirão Preto Medical School General Hospital. Their respective medical files were retrieved from the hospital's Medical Archive Service. For histopathological analysis, only incisional biopsies were included in this study. The histopathological analysis was evaluated by an experienced pathologist (ARS). In the evaluation of the patients' medical records, the following information was retrieved: age, sex, primary tumor topography, consumption of tobacco and alcoholic beverages, histological classification, relapses, metastases, death and histological grade. According to Barnes and collaborators [21], grade I is considered well differentiated, grade II is considered moderately differentiated, and grade III is considered poorly differentiated. We also analyzed disease-free survival (DFS), metastasis-free survival (MFS) and overall survival (OS).

\section{Tissue microarray construction}

The hematoxylin and eosin slides were reviewed by an experienced pathologist (ARS) to delineate the most significant area of each tumor to be used for the preparation of a tissue microarray (TMA). From the premarked donor paraffin blocks, $2 \mathrm{~mm}$ diameter cylinders were removed and sorted into a paraffin block recipient using the Tissue Microarray Builder Kit (TMA) (Histopathology Ltd., Hungary). From each TMA block, histological sections of $4 \mu \mathrm{m}$ thickness were prepared on a conventional rotating microtome (Leica RM2125RTS, Germany).

\section{Immunohistochemistry}

All tissue samples were routinely fixed in $4 \%$ formalin and paraffin embedded. The paraffin sections were dewaxed in xylol and rehydrated in a series of alcohols $(95,80$, and $70 \%$ ). Antigen retrieval was performed using a steam cooker with citrate buffer at $\mathrm{pH} 6.0$ for $40 \mathrm{~min}$ and then cooling for $40 \mathrm{~min}$. Endogenous peroxidase blocking was performed by solutions provided by the Kit Reveal (Biogen Cambridge, MA). After this procedure, the primary antibody was incubated for $1 \mathrm{~h}$ at room temperature. The primary antibody used in this study was against Chk2 (antibody NCL-chk2, clone DCS 270.1, against Prokaryotic GST-Chk2 fusion protein) with a 1:50 dilution of the Mouse Monoclonal Antibody (Novostain Super ABC Kit, Novocastra, Newcastle upon Tyne, UK). After incubation with the primary antibody, the sections were incubated with the Reveal buffer. After $10 \mathrm{~min}$, the sections were then incubated with the HRP amplification system for 15 min (both part of the Biogen Kit). The reaction was stained with diaminobenzidine (DAB) and counterstained with hematoxylin. The sections were then hydrated in distilled water and dehydrated in a series of alcohols and xylol. The slides were then covered with coverslips with the aid of Entellan (Merck, Germany). Normal skin tissue was used as a positive control for Chk2 negative controls were obtained by suppressing the primary antibodies. The slides were analyzed under a standard light microscope (Leica, DM 4000B, Germany). All TMA cylinders were examined, and all the cases showed Chk2 nuclear marking. For this reason, we stratified them into high and low expression groups. Samples were considered to have low expression if they showed positivity for Chk 2 in up to $66 \%$ of cells 
Table 1 Immunohistochemical expression of Chk2 and clinicopathological parameters evaluated in this study

\begin{tabular}{|c|c|c|}
\hline Feature & & No $(\%)$ of patients $(N=101)$ \\
\hline \multirow[t]{2}{*}{ Chk2 } & High expression & $58(57.43 \%)$ \\
\hline & Low expression & $43(42.57 \%)$ \\
\hline \multirow[t]{2}{*}{ Sex } & Male & $88(87.13 \%)$ \\
\hline & Female & $13(12.87 \%)$ \\
\hline \multirow[t]{3}{*}{ Age } & $<40$ & $03(2.97 \%)$ \\
\hline & $41-60$ & 49 (48.5\%) \\
\hline & $>60$ & $49(48.51 \%)$ \\
\hline \multirow[t]{3}{*}{ Smoking } & Yes & $81(80.20 \%)$ \\
\hline & No & $18(17.82 \%)$ \\
\hline & No information & $02(1.98 \%)$ \\
\hline \multirow[t]{3}{*}{ Alcohol consumption } & Yes & $78(77.23 \%)$ \\
\hline & No & $21(20.79 \%)$ \\
\hline & No information & $02(1.98 \%)$ \\
\hline \multirow[t]{6}{*}{ Staging } & $\mathrm{ECl}$ & $04(3.96 \%)$ \\
\hline & ECII & $11(10.89 \%)$ \\
\hline & ECIII & $14(13.86 \%)$ \\
\hline & ECIV & $33(32.67 \%)$ \\
\hline & In situ & $01(0.99 \%)$ \\
\hline & No information & $38(37.62 \%)$ \\
\hline \multirow[t]{6}{*}{ Tumor size } & $\mathrm{T} 1$ & 05 (5.00\%) \\
\hline & $\mathrm{T} 2$ & $21(20.79 \%)$ \\
\hline & T3 & $11(10.89 \%)$ \\
\hline & T4 & $26(25.74 \%)$ \\
\hline & No information & $37(36.63 \%)$ \\
\hline & In situ & $01(0.99 \%)$ \\
\hline \multirow[t]{2}{*}{ Regional metastasis } & Yes & $40(39.60 \%)$ \\
\hline & No & $61(60.40 \%)$ \\
\hline \multirow[t]{2}{*}{ Distant metastasis } & Yes & $16(15.84 \%)$ \\
\hline & No & $85(84.16 \%)$ \\
\hline \multirow[t]{4}{*}{ Tumor histological grade } & Well & $27(26.73 \%)$ \\
\hline & Moderate & $63(62.38 \%)$ \\
\hline & Poor & 10 (9.90\%) \\
\hline & No information & 01 (0.99\%) \\
\hline \multirow[t]{3}{*}{ Relapse } & Yes & $43(42.57 \%)$ \\
\hline & No & $56(55.45 \%)$ \\
\hline & No information & 02 (1.98\%) \\
\hline \multirow[t]{2}{*}{ Death } & Yes & 57 (56.44\%) \\
\hline & No & 45 (43.56\%) \\
\hline
\end{tabular}

*Statistical significance determined as $p \leq 0.05$

(nuclear staining, regardless of intensity) and were considered to have high expression if they showed positivity for Chk2 in more than $66 \%$ of cells (nuclear staining, regardless of intensity). This methodology was adapted from Lee and collaborators [22].
Table 2 Chk2 expression according to clinicopathological features in oral squamous cell carcinoma

\begin{tabular}{|c|c|c|c|}
\hline \multirow[t]{2}{*}{ Feature } & \multicolumn{2}{|l|}{ Chk2 } & \multirow{2}{*}{$\begin{array}{l}p- \\
\text { value }\end{array}$} \\
\hline & High & Low & \\
\hline \multicolumn{4}{|l|}{ Sex } \\
\hline Male & 50 & 38 & \multirow[t]{2}{*}{0.748} \\
\hline Female & 08 & 05 & \\
\hline \multicolumn{4}{|l|}{ Age } \\
\hline$<40$ & 01 & 02 & \multirow[t]{3}{*}{0.574} \\
\hline $41-60$ & 27 & 22 & \\
\hline$>60$ & 30 & 19 & \\
\hline \multicolumn{4}{|l|}{ Smoking } \\
\hline Yes & 47 & 34 & \multirow[t]{2}{*}{0.534} \\
\hline No & 09 & 09 & \\
\hline \multicolumn{4}{|c|}{ Alcohol consumption } \\
\hline Yes & 45 & 33 & \multirow[t]{2}{*}{0.663} \\
\hline No & 11 & 10 & \\
\hline \multicolumn{4}{|l|}{ Staging } \\
\hline $\mathrm{ECl}$ & 01 & 03 & \multirow[t]{5}{*}{0.243} \\
\hline ECll & 09 & 02 & \\
\hline ECIII & 07 & 07 & \\
\hline ECIV & 19 & 14 & \\
\hline In situ & 01 & 00 & \\
\hline \multicolumn{4}{|l|}{ Tumor size } \\
\hline T1 & 02 & 03 & \multirow[t]{5}{*}{0.686} \\
\hline $\mathrm{T} 2$ & 14 & 07 & \\
\hline T3 & 06 & 05 & \\
\hline T4 & 14 & 12 & \\
\hline In situ & 01 & 00 & \\
\hline \multicolumn{4}{|c|}{ Regional metastasis } \\
\hline Yes & 23 & 17 & \multirow[t]{2}{*}{0.99} \\
\hline No & 35 & 26 & \\
\hline \multicolumn{4}{|c|}{ Distant metastasis } \\
\hline Yes & 09 & 07 & \multirow[t]{2}{*}{0.917} \\
\hline No & 49 & 36 & \\
\hline \multicolumn{4}{|c|}{ Tumor histological grade } \\
\hline Well & 12 & 15 & \multirow[t]{3}{*}{0.302} \\
\hline Moderate & 39 & 24 & \\
\hline Poor & 06 & 04 & \\
\hline \multicolumn{4}{|l|}{ Relapse } \\
\hline Yes & 24 & 19 & \multirow[t]{2}{*}{0.756} \\
\hline No & 33 & 23 & \\
\hline \multicolumn{4}{|l|}{ Death } \\
\hline Yes & 31 & 25 & \multirow[t]{2}{*}{0.639} \\
\hline No & 27 & 18 & \\
\hline
\end{tabular}

* Statistical significance determined as $p \leq 0.05$ 


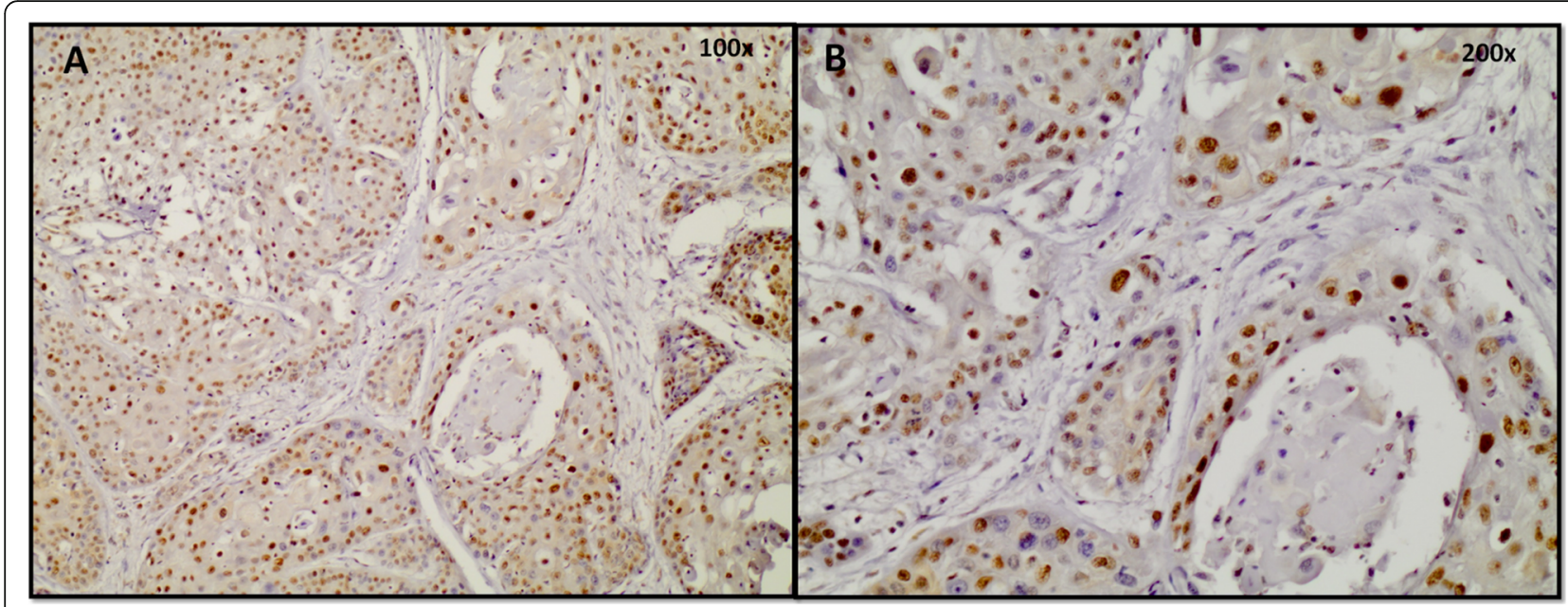

Fig. 1 Oral squamous cell carcinoma positive for Chk2 (nuclear staining). a immunohistochemistry, $\times 100$; b immunohistochemistry, $\times 200$

\section{Statistical analysis}

One hundred and one cases were included in the statistical analysis. Statistical analysis was performed using SPSS software version 22. Data analyses, obtained through the medical records, were performed using the chi-square test. To analyze the association of Chk2 with patient survival, DFS was estimated as the time between tumor resection and recurrence of the disease as a new primary tumor or metastasis. OS was calculated as the time between the diagnosis until the last follow-up or death of the patient, and MFS was estimated as the time elapsed between the initial diagnosis and the diagnosis of distant metastasis. Kaplan-Meier survival analysis was performed with the log-rank test. A significance level of $5 \%(p<0.05)$ was considered.

\section{Results}

\section{Epidemiological, clinical and pathological data}

A total of 101 patients were included in this study. Only $2.97 \%$ of the patients in our cohort were under 40 years of age, with a male to female ratio of 6.77:1. A significant percentage of the OSCC patients had reported simultaneous tobacco and alcohol consumption (81 of 101;
80.19\%). Regarding histological grading, 27 patients (26, $73 \%)$ showed well-differentiated tumors, 63 patients $(62$, $38 \%)$ showed moderately differentiated tumors, and 10 patients (9,90\%) presented poorly differentiated tumors. All demographic and clinical data are summarized in Table 1.

\section{Immunohistochemical findings and associations between Chk2 expression and clinicopathological features}

The nuclear expression of Chk2 was observed in all cases (101, 100\% cases), and the expression level was stratified into high and low expression, $>66$ and $<66 \%$, respectively (nuclear staining, adapted from Lee's study) [22]. Fiftyeight cases showed high expression (57.42\%), and 43 cases showed low expression (42.57\%).

The relationship between Chk2 expression and clinicopathological characteristics are shown in Table 2. Chk2 immunostaining is illustrated in Fig. 1a and b. We found no relationship between Chk2 expression and tumor size, with tumor size grouped as stage I/II and III/IV for statistical purposes $(p=0.243)$. There was also no correlation with sex $(p=0.748)$. There was no significant relationship between Chk2 expression and alcohol consumption $(p=0.663)$, tobacco consumption $(p=0.534)$, regional metastasis $(p=$
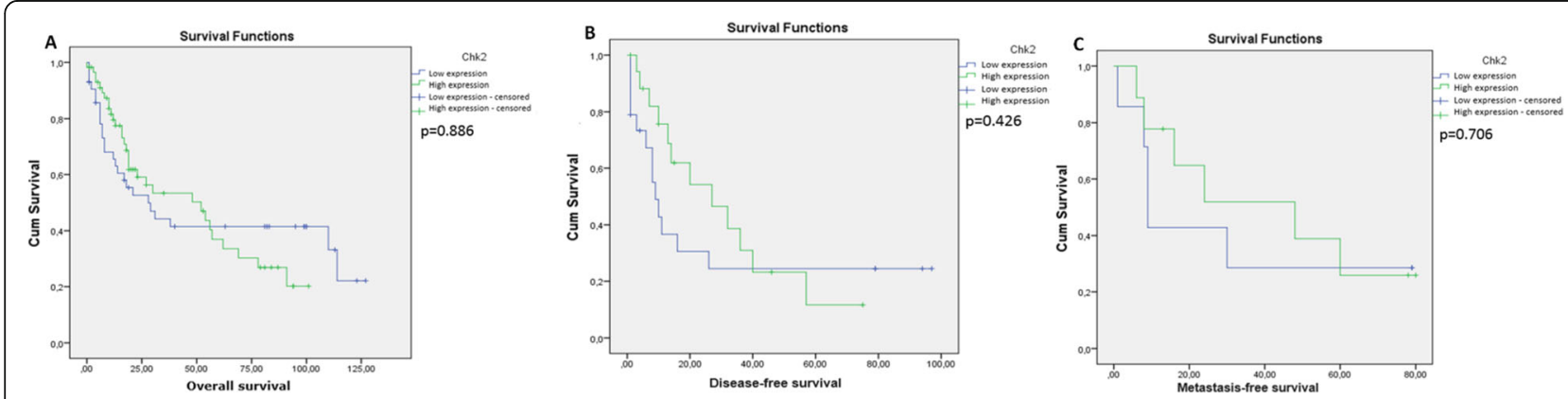

Fig. 2 Survival analysis (in months) according to Chk2 expression. a Overall survival. b Disease-free survival. c Metastasis-free survival 
990), distant metastasis $(p=0.917)$ or histological grade $(\mathrm{p}=0,302)$. These data are summarized in Table 2 .

\section{Survival analysis}

The follow-up period for the OSCC patients in this investigation ranged from 0 to 127 months (mean $=35.63$ months). The median survival time was 18.5 months. The 5 -year disease-specific survival rate was $38.88 \%$. The result of the overall survival analysis is shown in Fig. 2a. The result of the disease-free survival analysis is demonstrated in Fig. 2b, and the result of the metastasis-free survival analysis is demonstrated in Fig. 2c.

\section{Discussion}

Research related to OSCC has progressed, and several prognostic and predictive biomarkers have been described in the literature. However, so far, no biomarker is unanimously accepted for routine clinical use in OSCC [14]. To our knowledge, the present study is the first to study Chk2 immunoexpression in OSCC.

In carcinogenesis, the proper functioning of repair pathways is essential for a proper outcome in which cells with DNA damage can be repaired. Chk2 aids in the prevention of tumor progression, with attempts to prevent genomic instability, and can mobilize damaged DNA to repair. In addition, Chk2 can arrest the cell cycle and induce apoptosis in response to DNA damage [13].

In this study, the clinical and pathological data of the patients were in agreement with the data found in the literature. Similar to the study by Poeta and collaborators [23], the patients in our study were predominantly male (87.3\%), with advanced age (48.51\%), smoking history $(80.20 \%)$ and alcohol consumption (77.23\%). According to Montero and Patel [20], OSCC affects more men than women usually over 50 years of age, as in our study. However, more recent studies have shown the involvement of OSCC in younger patients, but this finding may be due to the early discovery of tumors and thus, may be defined as a change in the incidence of OSCC in patients less than 40 years old [24]. According to Adeel and colleagues [25], the incidence of OSCC in young people is considered low, in a total of 4 to $6 \%$ of cases, which was similar to our results, wherein only $2.97 \%$ of patients were under 40 years of age.

Older patients usually have a drinking habit that started early in adolescence or even early childhood. There is sufficient data in the literature on smoking as a crucial risk factor for the carcinogenesis of various types of cancer, such as lung cancer, esophageal cancer, stomach cancer, pancreatic cancer, liver cancer, ureter cancer, kidney cancer, bladder cancer, cervical cancer and OSCC [26]. Most of our patients (approximately 80\%) had some addiction, and the associated consumption with these two habits can increase the risk of developing OSCC up to 40 times [27].
Of the 101 patients in our series, 15.84\% developed distant metastases, in agreement with the study by de Bree et al. (2000) [28], where the distance metastasis rate was $16.8 \%$. Although distant metastases in the OSCC are considered low compared to other types of tumors, it is still a significant parameter to determinate OSCC prognosis [29].

Chk2 acts as a tumor suppressor and is considered a promising target for therapeutic and prognostic purposes. Many studies on Chk2 have associated its expression with different types of cancers, such as hepatocellular carcinoma [17], ovarian cancer [18] and bladder cancer [19]. However, the relationship between Chk2 and OSCC is still poorly understood. Therefore, the present study aimed to verify whether there was an association between Chk2 expression and OSCC progression. Our group had already analyzed Chk2 expression with other cancers, in which a relationship between Chk2 expression and lymph node metastasis in colon cancer patients had been seen, and the absence of Chk2 expression had been associated with better survival in these patients [16]. Our group also verified the association of Chk2 expression with breast cancer, in which we found an association between Chk2 expression and poor prognosis [15].

Currently, to the best of our knowledge, this is the first work that investigated the relationship between Chk2 expression and OSCC. Unfortunately, we did not find a significant relation between Chk2 expression and clinicopathological data or survival in OSCC. The sample size of 101 patients, as well as the short-term follow-up, may impose some limitations in our study. Another limitation is that the histological grade in biopsies may not correspond to the histological grade when evaluating the tumor as a whole because of sampling. Additional studies with larger sample sizes and longer follow-up times could improve the understanding of the role of Chk2 in OSCC.

\section{Conclusion}

In conclusion, our findings do not favor Chk2 as a prognostic marker in oral squamous cell carcinoma. However, further studies are needed to better understand the role of Chk2 in OSCC development.

\section{Abbreviations \\ Brca1: Breast cancer 1; Cdc25A: Cell Division Cycle 25A; Cdc25B: Cell Division Cycle 25B; Chk2: Checkpoint Kinase 2; DFS: Disease free survival; MFS: Metastasis free survival; OS: Overall survival; OSCC: Oral squamous cell carcinoma; P53: Protein 53; SCC: Squamous cell carcinoma; TMA: Tissue microarray}

\section{Acknowledgements}

We are thankful to technical assistance of Márcia Aparecida Ferreira Oliva e Laura Midori Kawasse. 


\section{Authors' contributions}

ARS, SCSC and AD designed the experiment, LYA and AD performed statistical analysis and wrote the manuscript. SCSC, AD, JEL and ARS interpreted and reviewed the experiment design, revised the proposal and guided the statistical analysis and critically reviewed the manuscript. All authors read and approved the final manuscript.

\section{Funding}

This research was funded by Fundação de Amparo à Pesquisa do Estado de São Paulo (FAPESP) and Conselho Nacional de Desenvolvimento Científico e Tecnológico (CNPq).

\section{Availability of data and materials}

The datasets analyzed during the current study are available from the first author upon reasonable request.

\section{Ethics approval and consent to participate}

The author declares no conflicts of interest associated with this manuscript. The patients' medical data were anonymized prior to access and analysis. The institutional review board (Permission number: 6116/2016) waived the need for written informed consent from study subjects because all potential patient-identifying information was removed prior to data analysis.

\section{Consent for publication}

Not applicable.

\section{Competing interests}

The authors declare that they have no competing interests.

\section{Author details}

'Department of Pathology and Forensic Medicine, Ribeirão Preto Medical School, University of São Paulo, Ribeirão Preto, Brazil. ${ }^{2}$ Hematology Division, Department of Clinical Medicine, Ribeirão Preto Medical School (FMRP/USP), University of São Paulo, Ribeirão Preto, São Paulo, Brazil. ${ }^{3}$ Department of Stomatology, Collective Health and Legal Dentistry, Ribeirão Preto School of Medicine, University of São Paulo, Ribeirão Preto, Brazil.

Received: 20 May 2019 Accepted: 27 February 2020

Published online: 18 March 2020

\section{References}

1. Szturz P, Vermorken JB. Treatment of elderly patients with squamous cell carcinoma of the head and neck. Front Oncol. 2016;6:199.

2. Pimenta Amaral TM, Da Silva Freire AR, Carvalho AL, Pinto CA, Kowalski LP. Predictive factors of occult metastasis and prognosis of clinical stages I and II squamous cell carcinoma of the tongue and floor of the mouth. Oral Oncol. 2004;40(8):780-6.

3. Young D, Xiao CC, Murphy B, Moore M, Fakhry C, Day TA. Increase in head and neck cancer in younger patients due to human papillomavirus (HPV). Oral Oncol. 2015:51(8):727-30.

4. Thomas GR, Nadiminti H, Regalado J. Molecular predictors of clinical outcome in patients with head and neck squamous cell carcinoma. Int J Exp Pathol. 2005;86(6):347-63.

5. Ahn JY, Schwarz JK, Piwnica-Worms H, Canman CE. Threonine 68 phosphorylation by ataxia telangiectasia mutated is required for efficient activation of Chk2 in response to ionizing radiation. Cancer Res. 2000;60(21): $5934-6$

6. Wu X, Webster SR, Chen J. Characterization of tumor-associated Chk2 mutations. J Biol Chem. 2001:276(4):2971-4.

7. Bell DW, Varley JM, Szydlo TE, Kang DH, Wahrer DC, Shannon KE, et al. Heterozygous germ line hCHK2 mutations in Li-Fraumeni syndrome. Science. 1999;286(5449):2528-31.

8. Li FP, Fraumeni JF, Mulvihill JJ, Blattner WA, Dreyfus MG, Tucker MA, et al. A cancer family syndrome in twenty-four kindreds. Cancer Res. 1988;48(18): 5358-62.

9. Falck J, Lukas C, Protopopova M, Lukas J, Selivanova G, Bartek J. Functional impact of concomitant versus alternative defects in the Chk2-p53 tumour suppressor pathway. Oncogene. 2001;20(39):5503-10.

10. Sullivan A, Yuille M, Repellin C, Reddy A, Reelfs $O$, Bell A, et al. Concomitant inactivation of p53 and Chk2 in breast cancer. Oncogene. 2002;21(9):1316-24.
11. Haruki N, Saito H, Tatematsu Y, Konishi H, Harano T, Masuda A, et al. Histological type-selective, tumor-predominant expression of a novel CHK1 isoform and infrequent in vivo somatic CHK2 mutation in small cell lung cancer. Cancer Res. 2000;60(17):4689-92.

12. Reddy A, Yuille M, Sullivan A, Repellin C, Bell A, Tidy JA, et al. Analysis of CHK2 in vulval neoplasia. Br J Cancer. 2002;86(5):756-60.

13. Bartek J, Lukas J. Mammalian G1- and S-phase checkpoints in response to DNA damage. Curr Opin Cell Biol. 2001;13(6):738-47.

14. Kim KY, McShane LM, Conley BA. Designing biomarker studies for head and neck cancer. Head Neck. 2014;36(7):1069-75.

15. Ribeiro-Silva A, Moutinho MA, Moura HB, Vale FR, Zucoloto S. Expression of checkpoint kinase 2 in breast carcinomas: correlation with key regulators of tumor cell proliferation, angiogenesis, and survival. Histol Histopathol. 2006;21(4):373-82.

16. Ribeiro KB, Zanetti JS, Ribeiro-Silva A, Pansani F, Garcia SB, Feres O, et al. CHK2 Immunohistochemical expression in Colon Cancer and its relation with Clinicopathological features and outcome in metastatic Colon Cancer patients. J Cytol Histol. 2014;5(6):1-5.

17. Carloni V, Lulli M, Madiai S, Mello T, Hall A, Luong TV, et al. CHK2 overexpression and mislocalisation within mitotic structures enhances chromosomal instability and hepatocellular carcinoma progression. Gut. 2018:67(2):348-61.

18. Szymanska-Pasternak J, Szymanska A, Medrek K, Imyanitov EN, Cybulski C, Gorski B, et al. CHEK2 variants predispose to benign, borderline and lowgrade invasive ovarian tumors. Gynecol Oncol. 2006;102(3):429-31.

19. Złowocka E, Cybulski C, Górski B, Debniak T, Słojewski M, Wokołorczyk D, et al. Germline mutations in the CHEK2 kinase gene are associated with an increased risk of bladder cancer. Int J Cancer. 2008;122(3):583-6.

20. Montero PH, Patel SG. Cancer of the oral cavity. Surg Oncol Clin N Am. 2015;24(3):491-508.

21. Barnes L, Eveson JW, Reichart P, Sidransky D. World Health Organization classification of Tumours. In: Pathology and genetics of head and neck Tumours. Lyon: IARC; 2005.

22. Lee HE, Han N, Kim MA, Lee HS, Yang HK, Lee BL, et al. DNA damage response-related proteins in gastric cancer: ATM, Chk2 and p53 expression and their prognostic value. Pathobiology. 2014;81(1):25-35.

23. Poeta ML, Manola J, Goldwasser MA, Forastiere A, Benoit N, Califano JA, et al. TP53 mutations and survival in squamous-cell carcinoma of the head and neck. N Engl J Med. 2007;357(25):2552-61.

24. Kapila SN, Natarajan S, Boaz K. A comparison of Clinicopathological differences in Oral squamous cell carcinoma in patients below and above 40 years of age. J Clin Diagn Res. 2017;11(9):ZC46-50.

25. Adeel M, Suhail A, Zaman SU. Squamous cell carcinoma of oral tongue in young patients - a 10 years tertiary care experience. J Pak Med Assoc. 2016;66(2):155-8.

26. International Agency for Research on Cancer. A review of human carcinogens. Personal habits and indoor combustion. IARC Working Group on the Evaluation of Carcinogenic Risks to Humans. IARC; 2012 Available from: https://monographs.iarc.fr/wp-content/uploads/2018/06/mono100E.pdf.

27. Marur S, Forastiere AA. Head and neck cancer: changing epidemiology, diagnosis, and treatment. Mayo Clin Proc. 2008;83(4):489-501.

28. de Bree R, Duerloo EE, Sow GB. Screening for distant metastasis in patients with head and neck cancer. Laryngoscope. 2000;110:397-401.

29. Majumdar B, Patil S, Sarode SC, Sarode GS, Rao RS. Clinico-pathological prognosticators in oral squamous cell carcinoma: An update. Transl Res in Oral Oncol. 2017;2:1-14.

\section{Publisher's Note}

Springer Nature remains neutral with regard to jurisdictional claims in published maps and institutional affiliations. 